\title{
Direct single-step surface plasmon resonance analysis of interactions between small peptides and immobilized monoclonal antibodies
}

\author{
Paula Gomes, Ernest Giralt, David Andreu * \\ Department of Organic Chemistry, University of Barcelona, Martí i Franquès 1-E-08028 Barcelona, Spain
}

Received 29 July 1999; received in revised form 20 September 1999; accepted 25 October 1999

\begin{abstract}
Surface plasmon resonance (SPR) methods have been optimized to permit direct kinetic analysis of the antigenic peptide analytes interacting with immobilized monoclonal antibodies (mAbs). High reproducibility and a significant correlation between SPR and previous ELISA data on the same set of antibodies and peptides were observed. The kinetic data obtained provide further insight into the structure of the main antigenic site of foot-and-mouth disease virus (FMDV). (C) 2000 Elsevier Science B.V. All rights reserved.
\end{abstract}

Keywords: BIAcore; Foot-and-mouth disease virus; Small antigenic peptides; Surface plasmon resonance

\section{Introduction}

The kinetics of biospecific binding between a macromolecule in solution and its receptor immobi-

\footnotetext{
Abbreviations: $\mathrm{C}_{\mathrm{A}}$, analyte concentration; EDC, $N$-ethyl- $N^{\prime}$ dimethylaminopropylcarbodiimide; ELISA, enzyme linked immunosorbent assay; FMDV, foot-and-mouth disease virus; $\mathrm{IC}_{50}$, $50 \%$ inhibition concentration; $k_{\mathrm{a}}$, association rate constant $\left(\mathrm{M}^{-1}\right.$ $\left.\mathrm{s}^{-1}\right) ; K_{\mathrm{A}}$, association thermodynamic constant $\left(\mathrm{M}^{-1}\right) ; k_{\mathrm{d}}$, dissociation rate constant $\left(\mathrm{s}^{-1}\right) ; K_{\mathrm{D}}$, dissociation thermodynamic constant $(\mathrm{M}) ; k_{\mathrm{s}}$, apparent rate constant $\left(\mathrm{s}^{-1}\right) ; \mathrm{mAb}$, monoclonal antibody; NHS, $N$-hydroxysuccinimide; PBS, phosphate buffer saline; $R$, SPR response at time $t(\mathrm{RU}) ; R_{\text {eq }}$, equilibrium response (RU); RI, bulk refractive index (RU); $R_{\max }$, maximum response (RU); $R_{\text {tot }}$, total SPR response (RU); RU, resonance units; SPR, surface plasmon resonance; $t_{\text {on }}$, run start time

* Corresponding author. Tel.: + 34-93-4021260; fax: +34-934021260; e-mail: andreu@admin.qo.ub.es
}

lized on a sensor surface can be measured by surface plasmon resonance (SPR). The response is proportional to the mass of the analyte that binds to the surface and the binding curve can be used to determine the kinetic parameters of the interaction. SPR biosensors are attractive because labelling of macromolecules is not required and real-time information on the course of binding is provided. In addition, the methodology is relatively independent of analyte concentration and purity (Fägerstam et al., 1992). We are interested in applying SPR analysis to kinetically characterize the interaction between peptides related to viral antigenic sites and relevant monoclonal antibodies (mAbs) (Van Regenmortel et al., 1994). In our research on foot-and-mouth disease virus (FMDV), we have used anti-FMDV mAbs and synthetic peptides reproducing the immunodominant 
region of the virus (antigenic site A, residues 136150 of envelope protein VP1, isolate C-S8c1) to examine the main structural features involved in the recognition of this site by mAbs (Carreño et al., 1992; Verdaguer et al., 1995; Feigelstock et al., 1996). Synthetic peptides reproducing different mutations at this site are particularly useful in identifying residues involved in recognition or escape events (Mateu et al., 1992; Verdaguer et al., 1998). Given the large number of such peptides and the relatively small number of relevant mAbs, the most productive approach would seem to be $\mathrm{mAb}$ immobilization and analysis of the peptides as soluble analytes. However, a limitation of SPR detection is that interactions between low molecular weight $(<5 \mathrm{kDa})$ analytes and their immobilized binding partners cannot, in principle, be studied directly since the increase in mass on the sensor chip is too small to provide reliable data.

It is known that bulk effects, together with nonspecific binding events, can affect true binding kinetics, particularly the direct detection of small analytes (Karlsson and Ståhlberg, 1995). A possible way to circumvent detection problems associated with small analytes is to use a competitive kinetic analysis where the low molecular weight analytes compete with a high molecular weight analyte for the same ligand binding site (Karlsson, 1994). However, this approach was not feasible in our case since a high molecular weight representative of antigenic site A, e.g., capsid protein VP1 of FMDV, is unavailable. In view of this, we have chosen to work with immobilized $\mathrm{mAb}$ and address the difficulties associated with the small size (about $1.6 \mathrm{kDa}$ ) of the peptide analytes. In a previous report, we demonstrated that the SPR experimental set-up could be optimized to obtain self-consistent kinetic data on the interaction between site A pentadecapeptides and mAb SD6 (Gomes et al., 2000).

In this paper, we present a definitive validation of our direct single-step SPR kinetic analysis and antigenicity ranking of small peptides. Using a panel of 44 FMDV site A-derived peptides and two anti-site A mAbs, we have obtained reliable kinetic parameters, good reproducibility and significant correlation with data previously obtained by ELISA (Verdaguer et al., 1998).

\section{Materials and methods}

\subsection{Equipment and reagents for SPR analysis}

BIAcore 1000 instrument, CM5 sensor chips, HBS buffer $(10 \mathrm{mM}$ Hepes with $0.15 \mathrm{M} \mathrm{NaCl}, 3.4 \mathrm{mM}$ EDTA and $0.005 \%$ surfactant $\mathrm{P} 20$ at $\mathrm{pH} 7.4$ ), amine coupling kit (NHS, $N$-hydroxysuccinimide; EDC, $N$-ethyl- $N$-dimethylaminopropylcarbodiimide) and ethanolamine were all obtained from Biosensor $\mathrm{AB}$ (Uppsala, Sweden). One hundred $\mathrm{mM}$ hydrochloric acid and $10 \mathrm{mM}$ sodium hydroxide were used as surface regeneration solutions.

\subsection{Peptide and $m A b$ solutions}

The antigenic site A is represented by the sequence $\mathrm{H}$-YTASARGDLAHLTTT- $\mathrm{NH}_{2}$ which we term peptide A15. The synthesis and purification of site A pentadecapeptides ${ }^{1}$ has been described elsewhere (Verdaguer et al., 1998) and the scrambled pentadecapeptide A15scr (H-RAGTATTLADLHYST- $\mathrm{NH}_{2}$ ) was synthesized by similar methods. Peptide stock solutions ca. $2.5 \mathrm{mM}$ in $0.1 \mathrm{M}$ acetic acid were prepared and assayed by amino acid analysis. Solutions for BIAcore analysis were prepared as 1000-fold and subsequent serial dilutions in HBS. Stock mAb solutions in PBS with $0.02 \%$ sodium azide, $\mathrm{pH}$ 7.3, were kindly supplied by Dr. Nuria Verdaguer (CSIC, Barcelona). mAb concentrations were determined by the Pierce BCA Assay (Pierce \& Co.) and the solutions for the preparation of biospecific $\mathrm{mAb}$ surfaces were used at $5 \mu \mathrm{g} \mathrm{ml}^{-1}$ final concentrations, following dilution in $10 \mathrm{mM}$ acetate buffer $\mathrm{pH}$ 5.0.

\subsection{Preparation of biosensor surfaces}

Immobilization of mAbs was performed according to manufacturer's instructions. A continuous flow

\footnotetext{
${ }^{1}$ Site A pentadecapeptides presenting mutations relative to the native sequence are denoted as "A15", followed by the position(s) of mutation(s) and the substitute amino acid letter(s) in parenthesis (e.g., the site A peptide corresponding to a mutation in position 138 to phenylalanine is called A15(138F)).
} 
of HBS $\left(5 \mu 1 \min ^{-1}\right)$ was maintained and the carboxymethyl surface was activated by a 7 min injection of a solution containing $0.2 \mathrm{M}$ EDC and $0.05 \mathrm{M}$ NHS. Biospecific surfaces were obtained by injecting 35 and $16 \mu \mathrm{l}$ of the SD6 and 4C4 solutions, respectively. Unreacted activated groups were blocked by a 6 min injection of ethanolamine and remaining non-covalently bound molecules were washed off with a $3 \mathrm{~min}$ pulse of $100 \mathrm{mM} \mathrm{HCl}$ or 10 $\mathrm{mM} \mathrm{NaOH}$ for SD6 or 4C4 surfaces, respectively. The final immobilization responses were typically around $1700 \mathrm{RU}$, which corresponds to a surface density of ca. $1.7 \mathrm{ng}(\mathrm{mAb}) \mathrm{mm}^{-2}$. Lower and higher mAb surface densities (ca. 0.5 and $3 \mathrm{ng} \mathrm{mm}^{2}$ ) for testing purposes (see Section 3) were also prepared, injecting 10 and $70 \mu \mathrm{l}$ of the SD6 solution and 5 and $45 \mu 1$ of the $4 \mathrm{C} 4$ solution, respectively.

\subsection{Biosensor kinetic analysis}

All kinetic SPR analyses were run in HBS at a flow rate of $60 \mu \mathrm{l} \mathrm{min} \mathrm{mi}^{-1}$ and each peptide was analyzed at six different concentrations, ranging from ca. 80 to $2500 \mathrm{nM}$ for SD6 and ca. 40 to $1250 \mathrm{nM}$ for $4 \mathrm{C} 4$. Sensorgrams were generated by the injection of peptide solutions with $90 \mathrm{~s}$ association steps followed by $240 \mathrm{~s}$ dissociation in running buffer ("kinjection" mode). A 90 s pulse of $100 \mathrm{mM} \mathrm{HCl}$ or $10 \mathrm{mM} \mathrm{NaOH}$ (SD6 and 4C4 surfaces, respectively) was applied to regenerate the surfaces at the end of each cycle and wash steps were added to avoid carry-over.

The pentadecapeptide A15scr, containing the constituent amino acids of A15 in scrambled form, was injected under the same conditions as a control for non-specific binding to the immobilized mAbs.

Some kinetic analyses were run in a similar way on lower and higher density mAb surfaces and at

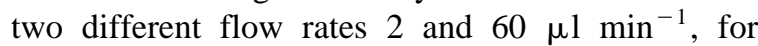
testing purposes (see Section 3). At the lower flow rate, $5 \mathrm{~min}$ association steps, $7 \mathrm{~min}$ dissociation steps and 2 min regeneration pulses were used.

\subsection{Data analysis}

Biosensor data were prepared, modelled and fitted by means of BIAEvaluation 3.0.1 software. Calcula- tions were carried out by numerical integration (Morton et al., 1995) and global curve fitting was done by non-linear least-squares analysis (O'Shannessy et al., 1993) applied simultaneously to the entire data set (Karlsson and Fält, 1997; Malmqvist and Karlsson, 1997). The quality of the fitted data was evaluated by comparison between calculated and experimental curves and by the magnitude of the $\chi^{2}$ parameters as well as the standard errors associated with the determined constants. The experimental sensorgrams were also compared to simulated curves constructed from the parameters determined by the BIAEvaluation software.

\subsection{Studies on reproducibility and correlation with ELISA}

The reproducibility of the SPR kinetic analysis was evaluated for a set of six site A peptides displaying different mutations from the reference A15 sequence and distinct antigenic behaviour. Each peptide was analyzed six times and standard deviations associated with the experimental kinetic constants were determined.

In order to evaluate the correlation between peptide antigenicities derived from SPR experiments and those previously determined by ELISA (Verdaguer et al., 1998), a panel of 44 site A peptides was analyzed over SD6 and 4C4 biospecific surfaces. Affinity constants derived from these analyses were then normalized to the A15 reference sequence and correlated with normalized $\mathrm{IC}_{50}$ values obtained in parallel ELISA experiments.

\section{Results and discussion}

An adaptation of SPR protocols permitting reliable kinetic analysis of small soluble peptide analytes binding to immobilized mAbs has been previously described (Gomes et al., 2000). This preliminary study identified several key features for a successful analysis: (i) high flow rates and (ii) high peptide concentrations to avoid mass-transport limitations, and (iii) medium-density mAb surfaces to minimize ligand site heterogeneity (O'Shannessy and Winzor, 1996; Myszka et al., 1997; Oddie et al., 1997). 
The goal of the present study was two-fold. On the one hand, we wished to further illustrate the applicability of our methodology by expanding it to a larger set of site A peptides and two anti-site A mAbs of distinct reactivity, SD6 and 4C4. Secondly, we sought to validate the method by demonstrating the reproducibility of our SPR analyses as well as the correlation between affinity parameters derived from biosensor experiments and parallel data from classical competition ELISA studies (Verdaguer et al., 1998).

\subsection{Adapting the experimental set-up to a different $m A b$}

The immobilization conditions successfully used for SD6 (Gomes et al., 2000) did not prove readily adaptable to mAb $4 \mathrm{C} 4$. This antibody coupled more efficiently than SD6 to the activated carboxymethyl dextran matrix and thus required lower injection volumes of 4C4 to achieve surface densities comparable to those previously obtained with SD6. Another important difference between the antibodies was that 4C4 surfaces were not suitably regenerated by 100 $\mathrm{mM} \mathrm{HCl}$. A clear symptom of ineffective regeneration was that sensorgrams from the same 4C4 surface showed an increase in baseline response and a concomitant decrease in signal for identical A15 concentrations over repetitive cycles (data not shown). Alternative regeneration procedures, using other acids (phosphoric or formic) or bases $(10 \mathrm{mM}$ glycine $\mathrm{pH} 12 ; 10 \mathrm{mM}$ sodium hydroxide), were tested and sodium hydroxide was found to be the most efficient regenerating agent.

Further, while for SD6 the optimal peptide concentration range was between 75 and $2500 \mathrm{nM}$, for $4 \mathrm{C} 4$ it was between 35 and $1250 \mathrm{nM}$. This difference was apparently due to surface saturation at high peptide concentrations, since 4C4 displayed higher affinities (Table 1) than SD6 (Gomes et al., 2000).

With these adaptations, the $R_{\max }$ measured on freshly prepared 4C4 surfaces was within $85-95 \%$ of the value expected from immobilization response (for a 1:1 interaction), and the mAb was found to be

Table 1

Kinetic data, corrected for non-specific binding, obtained in the biosensor analysis of the interactions between $\mathrm{mAb} 4 \mathrm{C} 4$ and 44 site $\mathrm{A}$ peptides. Qualitative relative antigenicities obtained from ELISA competition assays are represented, with a black box corresponding to $\mathrm{IC}_{50}>100$, a dark grey box to $\mathrm{IC}_{50}=30$ to 100 , a light grey box to $\mathrm{IC}_{50}=5$ to 30 and a white box to $\mathrm{IC}_{50}<5$. "n.i." - No interaction could be reliably measured

\begin{tabular}{|c|c|c|c|c|c|c|c|c|c|}
\hline PEPTIDE & $\mathrm{k}_{\mathrm{a}} / \mathrm{M}^{-1} \mathrm{~s}^{-1}$ & $\mathbf{k}_{\mathrm{d}} / \mathrm{s}^{-1}$ & $\mathrm{~K}_{\mathrm{A}} / \mathrm{M}^{-1}$ & ELISA & PEPTIDE & $\mathrm{k}_{\mathrm{i}} / \mathrm{M}^{-1} \mathrm{~s}^{-1}$ & $k_{d} / s^{-1}$ & $\mathbf{K}_{\mathrm{A}} / \mathrm{M}^{-1}$ & ELISA \\
\hline A15 & $3.8 \times 10^{5}$ & $1.9 \times 10^{-3}$ & $1.9 \times 10^{8}$ & & A15(148S) & $3.0 \times 10^{5}$ & $7.9 \times 10^{-3}$ & $3.8 \times 10^{7}$ & \\
\hline $\mathrm{A} 15(137 \mathrm{P})$ & $1.2 \times 10^{5}$ & $6.1 \times 10^{-4}$ & $2.0 \times 10^{8}$ & & $\operatorname{A15}(138 D)$ & n.i. & n.i. & n.i. & \\
\hline A15(138P) & $4.1 \times 10^{5}$ & $5.1 \times 10^{-2}$ & $8.0 \times 10^{6}$ & & $\mathrm{A15}(138 \mathrm{E})$ & n.i. & n.i. & n.i. & \\
\hline $\mathrm{A} 15$ (139P) & n.i. & n.i. & n.i. & & $\operatorname{A15}(138 F)$ & $5.5 \times 10^{5}$ & $5.7 \times 10^{-3}$ & $9.8 \times 10^{7}$ & \\
\hline $\mathrm{A} 15(140 \mathrm{P})$ & $1.9 \times 10^{5}$ & $1.9 \times 10^{-3}$ & $1.0 \times 10^{8}$ & & $\operatorname{A15}(138 \mathrm{~K})$ & $3.5 \times 10^{5}$ & $2.3 \times 10^{-2}$ & $1.5 \times 10^{7}$ & \\
\hline $\operatorname{A15}(141 P)$ & n.i. & n.i. & n.i. & & $\operatorname{A15}(138 R)$ & $1.4 \times 10^{5}$ & $1.9 \times 10^{-2}$ & $7.4 \times 10^{6}$ & \\
\hline $\operatorname{A15}(142 P)$ & n.i. & n.i. & n.i. & & $\operatorname{A15}(138 \mathrm{~V})$ & $2.7 \times 10^{5}$ & $1.4 \times 10^{-3}$ & $2.0 \times 10^{8}$ & \\
\hline A15(143P) & n.i. & n.i. & n.i. & & $\operatorname{A15}(138 Y)$ & $4.0 \times 10^{5}$ & $1.3 \times 10^{-3}$ & $3.0 \times 10^{8}$ & \\
\hline $\mathrm{A15}(144 \mathrm{P})$ & n.i. & n.i. & n.i. & & $\mathrm{A} 15(145 \mathrm{D})$ & n.i. & n.i. & n.i. & \\
\hline $\mathrm{A} 15(145 \mathrm{P})$ & n.i. & n.i. & n.i. & & $\operatorname{A15}(145 E)$ & $1.5 \times 10^{5}$ & $2.2 \times 10^{-3}$ & $6.9 \times 10^{7}$ & \\
\hline $\mathrm{A15}(146 \mathrm{P})$ & n.i. & n.i. & n.i. & & $\operatorname{A15}(145 \mathrm{~F})$ & $1.4 \times 10^{5}$ & $5.1 \times 10^{-3}$ & $2.7 \times 10^{7}$ & \\
\hline $\mathrm{A} 15(147 \mathrm{P})$ & n.i. & n.i. & n.i. & & $\operatorname{A15}(145 \mathrm{I})$ & $1.7 \times 10^{5}$ & $6.4 \times 10^{-3}$ & $2.7 \times 10^{7}$ & \\
\hline $\operatorname{A15}(148 P)$ & $1.6 \times 10^{5}$ & $1.4 \times 10^{-2}$ & $1.2 \times 10^{7}$ & & $\operatorname{A15}(145 K)$ & $2.5 \times 10^{5}$ & $2.3 \times 10^{-3}$ & $1.1 \times 10^{8}$ & \\
\hline A15(137S) & $1.7 \times 10^{5}$ & $3.0 \times 10^{-3}$ & $5.6 \times 10^{7}$ & & $\mathrm{~A} 15(145 \mathrm{R})$ & $6.6 \times 10^{4}$ & $5.9 \times 10^{-3}$ & $1.1 \times 10^{7}$ & \\
\hline A15(138S) & $2.5 \times 10^{5}$ & $2.2 \times 10^{-3}$ & $1.1 \times 10^{8}$ & & A15(147A) & n.i. & n.i. & n.i. & \\
\hline $\mathrm{A} 15(140 \mathrm{~S})$ & $2.5 \times 10^{5}$ & $2.4 \times 10^{-3}$ & $1.1 \times 10^{8}$ & & $\mathrm{~A} 15(147 \mathrm{D})$ & n.i. & n.i. & n.i. & \\
\hline $\operatorname{A15}(141 S)$ & $1.2 \times 10^{5}$ & $3.5 \times 10^{-3}$ & $3.2 \times 10^{7}$ & & $\mathrm{~A} 15(147 \mathrm{E})$ & n.i. & n.i. & n.i. & \\
\hline $\operatorname{A15}(142 S)$ & $6.3 \times 10^{4}$ & $3.8 \times 10^{-3}$ & $1.6 \times 10^{7}$ & & $\operatorname{A15}(147 G)$ & n.i. & n.i. & n.i. & \\
\hline A15(143S) & n.i. & n.i. & n.i. & & $\operatorname{A15}(147 \mathrm{~K})$ & n.i. & n.i. & n.i. & \\
\hline A15(144S) & n.i. & n.i. & n.i. & & $\operatorname{A15}(147 N)$ & n.i. & n.i. & n.i. & \\
\hline A15(145S) & $3.8 \times 10^{5}$ & $7.6 \times 10^{-3}$ & $5.1 \times 10^{7}$ & & $\mathrm{~A} 15(147 \mathrm{R})$ & n.i. & n.i. & n.i. & \\
\hline $\mathrm{A} 15(147 \mathrm{~S})$ & n.i. & n..... & n.i. & & $\mathrm{A} 15(147 \mathrm{~V})$ & $1.4 \times 10^{5}$ & $5.6 \times 10^{-2}$ & $2.5 \times 10^{6}$ & \\
\hline
\end{tabular}


resistant over more than 100 analyses and alkaline regeneration cycles.

\subsection{Quality of the fitted data}

A particular concern of the present work was to obtain self-consistent and reliable data. To this end, we first evaluated the non-specific response given by A15Scr, a peptide with the same amino acid composition of the reference A15 but with a scrambled sequence (see Section 2). The binding kinetics of this peptide over a concentration range identical to site $\mathrm{A}$ peptides produced sensorgrams similar to "square waves", reflecting a pure $R I$ jump without any significant biospecific interaction (Fig. 1). Nevertheless, since high peptide concentrations are known to cause higher bulk $R I$, baseline drifts and altered binding due to a higher probability of non-specific analyte retention within the dextran matrix (Schuck, 1997a,b), a correction of the binding curves for every site A peptide by subtracting the corresponding sensorgrams of A15Scr was decided. Even though peptide solution preparations were strictly identical, different bulk refractive indices were observed for different peptide runs, probably due to factors such as temperature fluctuations, instrumental drift, variations in sample dilution or sample dispersion at the moment of injection. Therefore, sensorgram correc- tion was not always accompanied by total elimination of bulk $R I$ (Fig. 2A,B).

Corrected sensorgrams were readily fitted to the 1:1 Langmuirian interaction model, suggesting that binding is properly described by the rate equation of a $\mathrm{A}+\mathrm{B} \Leftrightarrow \mathrm{AB}$ pseudo-first order interaction:

$\mathrm{d}[\mathrm{AB}] / \mathrm{d} t=k_{\mathrm{a}}[\mathrm{A}][\mathrm{B}]-k_{\mathrm{d}}[\mathrm{AB}]$

which, in terms of SPR response, is given by:

$\mathrm{d}[\mathrm{AB}] / \mathrm{d} t=\mathrm{d} R / \mathrm{d} t=k_{\mathrm{a}} C_{\mathrm{A}}\left(R_{\text {max }}-R\right)-k_{\mathrm{d}} R$.

Sometimes, it was necessary to include baseline drift in the fitting model, due to instrumental fluctuations that affected the total response $\left(R_{\text {tot }}\right)$ :

$R_{\text {tot }}=R+R I+\operatorname{drift}\left(t-t_{\text {on }}\right)$

where drift is given in $\mathrm{RU} / \mathrm{s}$ and $t-t_{\mathrm{on}}$ is the elapsed time since start of the run.

Experimental and theoretical curves were fully superimposable (Fig. 2C), with a random distribution of residuals within \pm 2 RU (occasionally higher at injection plugs), and $\chi^{2}$ values typically less than 1 . Standard errors associated to the fitted $k_{\mathrm{a}}, k_{\mathrm{d}}$ and $R_{\max }$ parameters were consistently below $3 \%, 5 \%$ and $2 \%$, respectively (data not shown).

Evaluation of mass-transport influence on kinetic data is often advisable (Schuck, 1997a,b). Tests

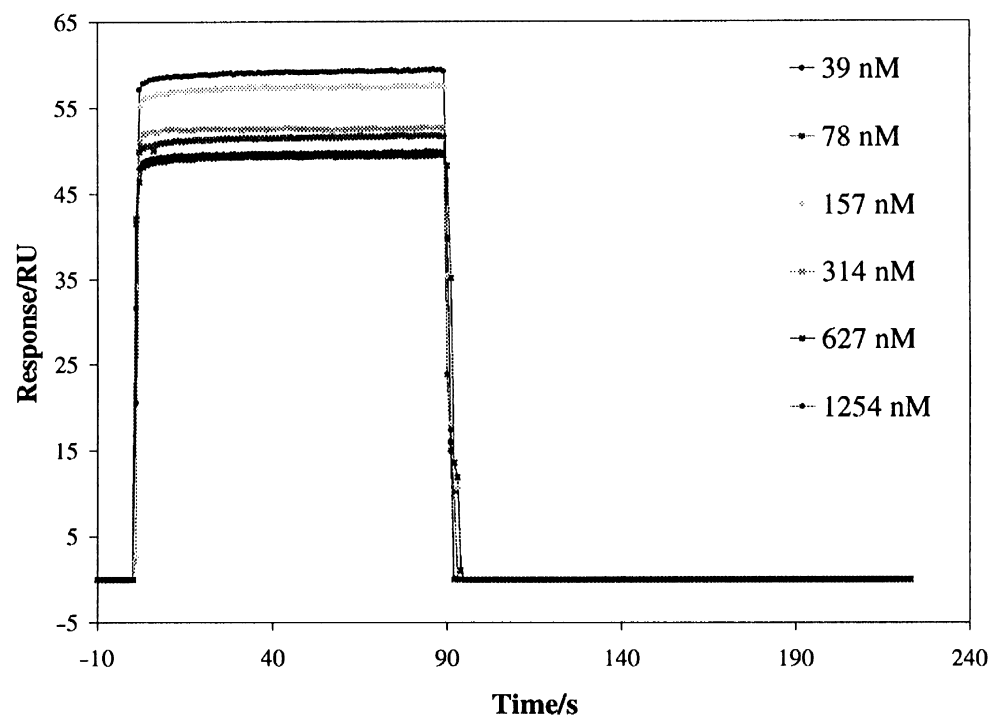

Fig. 1. Binding curves for non-specific peptide A15Scr. 

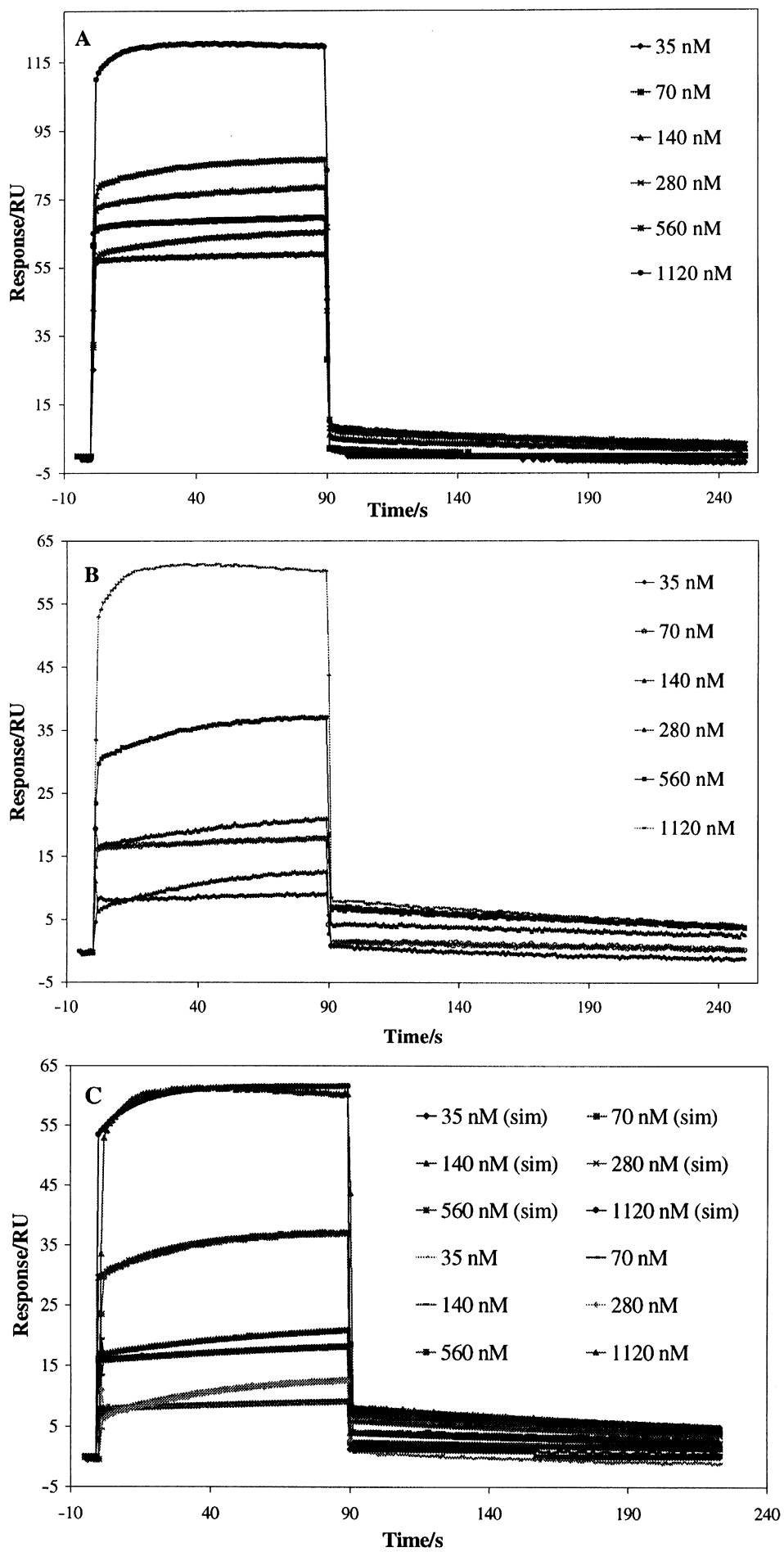
Table 2

Kinetic data obtained for the mAb SD6/peptide A15 and mAb 4C4/peptide A15 binding interactions under different buffer flow rate and surface density conditions

\begin{tabular}{|c|c|c|c|c|c|c|}
\hline \multirow{2}{*}{$\begin{array}{l}\text { Buffer flow rate } \\
\left(\mu 1 \min ^{-1}\right)\end{array}$} & \multicolumn{3}{|c|}{$\mathrm{SD} 6 / \mathrm{ng} \mathrm{mm}^{-2}$} & \multicolumn{3}{|c|}{$4 \mathrm{C} 4 / \mathrm{ng} \mathrm{mm}^{-2}$} \\
\hline & 0.5 & 1.6 & 2.5 & 0.4 & 1.7 & 2.7 \\
\hline 60 & $\mathrm{a}$ & $\begin{array}{l}k_{\mathrm{a}}=5.9 \times 10^{4} \mathrm{M}^{-1} \mathrm{~s}^{-1} \\
k_{\mathrm{d}}=1.3 \times 10^{-3} \mathrm{~s}^{-1} \\
\chi^{2}=0.3 \\
k_{\mathrm{a}}=7.3 \times 10^{4} \mathrm{M}^{-1} \mathrm{~s}^{-1} \\
k_{\mathrm{d}}=1.4 \times 10^{-3} \mathrm{~s}^{-1} \\
\chi^{2}=0.2\end{array}$ & $\begin{array}{l}k_{\mathrm{a}}=9.0 \times 10^{4} \mathrm{M}^{-1} \mathrm{~s}^{-1} \\
k_{\mathrm{d}}=1.2 \times 10^{-3} \mathrm{~s}^{-1} \\
\chi^{2}=1.1 \\
k_{\mathrm{a}}=1.1 \times 10^{5} \mathrm{M}^{-1} \mathrm{~s}^{-1} \\
k_{\mathrm{d}}=1.8 \times 10^{-3} \mathrm{~s}^{-1} \\
\chi^{2}=2.2\end{array}$ & a & $\begin{array}{l}k_{\mathrm{a}}=2.1 \times 10^{5} \mathrm{M}^{-1} \mathrm{~s}^{-1} \\
k_{\mathrm{d}}=1.6 \times 10^{-3} \mathrm{~s}^{-1} \\
\chi^{2}=2 \\
k_{\mathrm{a}}=3.8 \times 10^{5} \mathrm{M}^{-1} \mathrm{~s}^{-1} \\
k_{\mathrm{d}}=1.9 \times 10^{-3} \mathrm{~s}^{-1} \\
\chi^{2}=1.0\end{array}$ & $\begin{array}{l}k_{\mathrm{a}}=2.6 \times 10^{5} \mathrm{M}^{-1} \mathrm{~s}^{-1} \\
k_{\mathrm{d}}=8.4 \times 10^{-4} \mathrm{~s}^{-1} \\
\chi^{2}=0.4 \\
k_{\mathrm{a}}=5.0 \times 10^{5} \mathrm{M}^{-1} \mathrm{~s}^{-1} \\
k_{\mathrm{d}}=2.0 \times 10^{-3} \mathrm{~s}^{-1} \\
\chi^{2}=0.5\end{array}$ \\
\hline
\end{tabular}

${ }^{a}$ No reliable measurements could be made at this surface density.

should include analysis over a concentration range from 0.1 to $10 K_{\mathrm{D}}$, variation of the buffer flow rate and also variation of the binding capacity using different surface densities. In this work, we observed consistent results for peptides analyzed over a 33-fold concentration range, from as high as $10 K_{\mathrm{D}}$ down to ca. $40 \mathrm{nM}$. The $0.1 K_{\mathrm{D}}$ condition was possible only for peptides with $K_{\mathrm{D}}$ values at or above the $\mu \mathrm{M}$ level.

Mass-transport effects were evaluated on peptide A15 at two different buffer flow rates $(2$ and $60 \mu 1$ $\min ^{-1}$ ) and three different surface capacities (ca. $0.5,1.5$ and $3.0 \mathrm{ng} \mathrm{mm}^{2}$ ). Binding was not measurable at the lowest density surfaces. Higher densities (Table 2) did not show important differences in kinetic rate constants, as expected from the small size of the peptides. In fact, all the experimental curves fitted to the 1:1 Langmuirian interaction model and kinetic constants were only slightly smaller when

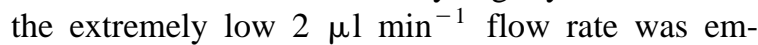
ployed. Mass-transport limitations are not usually dramatic for small analytes and can be avoided with correct experimental set-ups where high buffer flow rates and low density surfaces are employed. On the other hand, even when careful experimental design is applied and internal consistent data are obtained, one cannot rule out the possibility of diffusion-controlled kinetics. Hence, SPR-derived kinetic rate constants cannot be considered as absolutely "true" values. Nevertheless, the real usefulness of the technique lies in the comparative analysis of the kinetic behavior of analogous analytes screened under the same experimental conditions.

\subsection{Correlation of BIAcore data with previous anti- genicity studies by ELISA}

In order to evaluate the reproducibility of the data obtained in SPR analysis, six consecutive assays were performed for six peptides on a 4C4 surface. Given the small size of the analytes, the kinetic constants showed very good reproducibility, with standard deviations less than $9 \%$ of the mean values (Table 3).

Having found reliable operational conditions for two mAbs, our next concern was to evaluate the applicability of the technique for measurements of the antigenicity of small peptides representing relevant mutations from the consensus FMDV site A sequence reproduced by peptide A15. The antigenicity of 44 such peptides toward a panel of anti-FMDV mAbs (which included SD6 and 4C4) had already been evaluated by competition ELISA (Verdaguer et al., 1998). As was found for mAb SD6 (Gomes et al., 2000), a good correlation was also observed with mAb 4C4 (Table 1). Using A15 as standard, normalized relative affinities $\left[K_{\text {Drel }}\right.$ (peptide $x$ ) $=K_{\mathrm{D}}$ (peptide $x$ ) $\left./ K_{\mathrm{D}}(\mathrm{A} 15)\right]$ were derived from SPR data, as well as from ELISA experiments $\left[\mathrm{IC}_{50 \mathrm{rel}}\right.$ (peptide $x$ ) $=\mathrm{IC}_{50}($ peptide $x$ )/

Fig. 2. Sensorgrams for binding of peptide A15(142S) to mAb 4C4: (A) Raw data; (B) Sensorgrams after correction for non-specific binding; (C) Overlay plot of experimental (corrected) and simulated (sim) sensorgrams (Note: Higher total $\left(R_{\text {tot }}\right)$ responses correspond to higher peptide concentrations, except for $280 \mathrm{nM}$ peptide injection (second smaller response) which presented a lower bulk RI jump). 
Table 3

Reproducibility of kinetic data in the biosensor analysis of the interactions between mAb 4C4 and six site A peptides. Each peptide was characterized in six independent analyses. "n.i." — No interaction could be reliably measured

\begin{tabular}{|c|c|c|c|c|c|c|c|}
\hline Peptide & Analysis \# & $k_{\mathrm{a}} / \mathrm{M}^{-1} \mathrm{~s}^{-1}$ & $k_{\mathrm{d}} / \mathrm{s}^{-1}$ & Peptide & Analysis \# & $k_{\mathrm{a}} / \mathrm{M}^{-1} \mathrm{~s}^{-1}$ & $k_{\mathrm{d}} / \mathrm{s}^{-1}$ \\
\hline \multirow[t]{7}{*}{ A15(138D) } & 1 & n.i. & n.i. & \multirow[t]{7}{*}{ A15(138R) } & $1^{\mathrm{a}}$ & $1.06 \times 10^{5}$ & $2.16 \times 10^{-2}$ \\
\hline & 2 & n.i. & n.i. & & 2 & $1.46 \times 10^{5}$ & $1.94 \times 10^{-2}$ \\
\hline & 3 & n.i. & n.i. & & 3 & $1.45 \times 10^{5}$ & $1.88 \times 10^{-2}$ \\
\hline & 4 & n.i. & n.i. & & 4 & $1.51 \times 10^{5}$ & $2.08 \times 10^{-2}$ \\
\hline & 5 & n.i. & n.i. & & 5 & $1.42 \times 10^{5}$ & $1.94 \times 10^{-2}$ \\
\hline & 6 & n.i. & n.i. & & 6 & $1.39 \times 10^{5}$ & $1.88 \times 10^{-2}$ \\
\hline & $\begin{array}{l}\text { mean } \\
\text { value } \pm S D\end{array}$ & - & - & & $\begin{array}{l}\text { mean } \\
\text { value } \pm S D\end{array}$ & $(1.45 \pm 0.05) \times 10^{5}$ & $(1.94 \pm 0.07) \times 10^{-2}$ \\
\hline \multirow[t]{7}{*}{ A15(138F) } & 1 & $5.54 \times 10^{5}$ & $5.06 \times 10^{-3}$ & \multirow[t]{7}{*}{ A15(138V) } & $1^{\mathrm{a}}$ & $2.56 \times 10^{5}$ & $6.59 \times 10^{-4}$ \\
\hline & 2 & $6.00 \times 10^{5}$ & $6.23 \times 10^{-3}$ & & 2 & $2.90 \times 10^{5}$ & $1.34 \times 10^{-3}$ \\
\hline & 3 & $4.70 \times 10^{5}$ & $5.44 \times 10^{-3}$ & & 3 & $2.49 \times 10^{5}$ & $1.15 \times 10^{-3}$ \\
\hline & 4 & $5.68 \times 10^{5}$ & $5.55 \times 10^{-3}$ & & 4 & $2.67 \times 10^{5}$ & $1.34 \times 10^{-3}$ \\
\hline & 5 & $5.70 \times 10^{5}$ & $6.04 \times 10^{-3}$ & & 5 & $2.72 \times 10^{5}$ & $1.60 \times 10^{-3}$ \\
\hline & $6^{\mathrm{a}}$ & $4.90 \times 10^{5}$ & $1.16 \times 10^{-3}$ & & 6 & $2.83 \times 10^{5}$ & $1.62 \times 10^{-3}$ \\
\hline & $\begin{array}{l}\text { mean } \\
\text { value } \pm S D\end{array}$ & $(5.5 \pm 0.5) \times 10^{5}$ & $(5.7 \pm 0.5) \times 10^{-3}$ & & $\begin{array}{l}\text { mean } \\
\text { value } \pm S D\end{array}$ & $(2.7 \pm 0.2) \times 10^{5}$ & $(1.4 \pm 0.2) \times 10^{-3}$ \\
\hline \multirow[t]{7}{*}{ A15(138K) } & 1 & $3.05 \times 10^{5}$ & $2.35 \times 10^{-2}$ & \multirow[t]{7}{*}{ A15(138Y) } & 1 & $4.46 \times 10^{5}$ & $1.41 \times 10^{-3}$ \\
\hline & 2 & $3.62 \times 10^{5}$ & $2.33 \times 10^{-2}$ & & 2 & $3.99 \times 10^{5}$ & $1.32 \times 10^{-3}$ \\
\hline & 3 & $3.74 \times 10^{5}$ & $2.33 \times 10^{-2}$ & & 3 & $4.05 \times 10^{5}$ & $1.12 \times 10^{-3}$ \\
\hline & 4 & $3.78 \times 10^{5}$ & $2.40 \times 10^{-2}$ & & 4 & $3.82 \times 10^{5}$ & $1.41 \times 10^{-3}$ \\
\hline & 5 & $3.38 \times 10^{5}$ & $2.25 \times 10^{-2}$ & & 5 & $3.80 \times 10^{5}$ & $1.48 \times 10^{-3}$ \\
\hline & $6^{\mathrm{a}}$ & $4.65 \times 10^{5}$ & $2.25 \times 10^{-2}$ & & 6 & $3.82 \times 10^{5}$ & $1.34 \times 10^{-3}$ \\
\hline & $\begin{array}{l}\text { mean } \\
\text { value } \pm S D\end{array}$ & $(3.5 \pm 0.3) \times 10^{5}$ & $(2.32 \pm 0.06) \times 10^{-2}$ & & $\begin{array}{l}\text { mean } \\
\text { value } \pm \mathrm{SD}\end{array}$ & $(4.0 \pm 0.3) \times 10^{5}$ & $(1.3 \pm 0.1) \times 10^{-3}$ \\
\hline
\end{tabular}

${ }^{\mathrm{a}} k_{\mathrm{a}}$ were regarded as outlying and were not considered for calculating mean and SD values.

$\left.\mathrm{IC}_{50}(\mathrm{~A} 15)\right]$. Fig. 3 shows the correlation between $K_{\text {Drel }}$ and $\mathrm{IC}_{50 \mathrm{rel}}$ values for the entire set of 44 peptides and two mAbs. Correlation coefficients of 0.96 (calculated from peptides giving measurable $K_{\mathrm{D}}$ and $\mathrm{IC}_{50}$ values) are impressive given the small size of the analytes and the fact that SPR and ELISA techniques differ in terms of procedure, detection and actual interaction phenomena. Thus, competitive ELISA is an indirect method, where each variant peptide competes with a reference sequence representative of the antigenic site, while in SPR direct $\mathrm{mAb}$-peptide interactions are monitored.

\subsection{Relevance to FMDV studies}

Antigenic site A is a key component of the immune response against FMDV, and some of its constituent amino acid residues play a decisive role in the mechanisms of FMDV escape under immune pressure (Martínez et al., 1991). The involvement of the RGD tripeptide motif in both antibody and host cell recognition, as well as the importance of key adjacent residues such as Leu 144 and Leu 147 were well-established in previous studies (Verdaguer et al., 1995; Hernández et al., 1996; Mateu et al., 1996; Verdaguer et al., 1998), where site A variant peptides proved very useful in probing the antigenic structure of this site. Since only equilibrium data have been reported so far, we have sought to expand the available information on the antigenic structure of site A by exploring the dynamic aspects of these interactions by SPR. We have chosen 43 analogues of peptide A15 (the site A reference peptide) to show how structural variation within site A can be correlated with and adequately explained by kinetic SPR data.

Our choice of peptides focused on several structural features of antigenic site A. We first performed a Pro scan from residues 137 to 148 of the $\mathrm{G}-\mathrm{H}$ loop. The well-known structure-disrupting effect of 

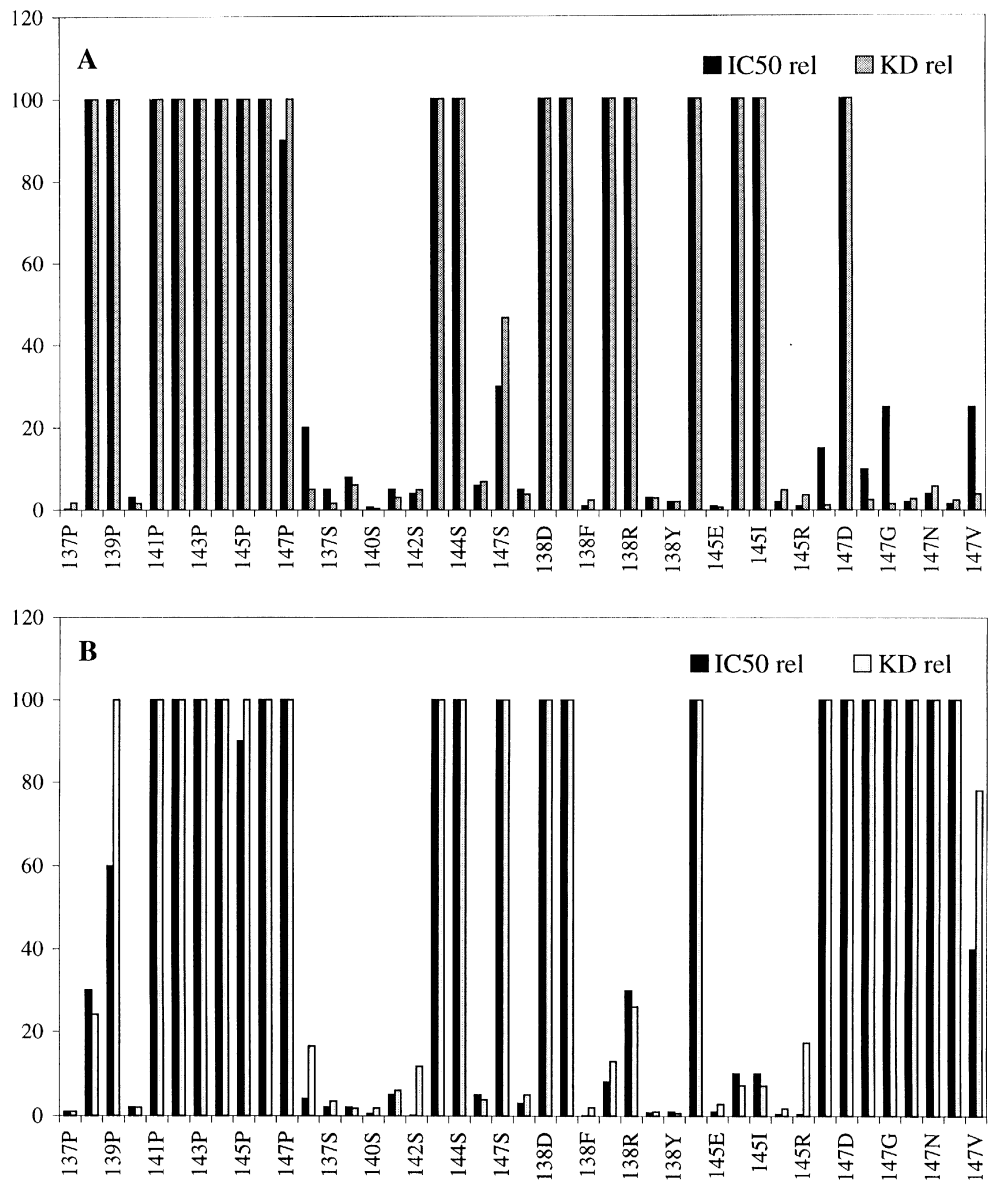

Fig. 3. Correlation between BIAcore $\left(K_{\mathrm{D} \text { rel }}\right)$ and ELISA $\left(\mathrm{IC}_{50 \text { rel }}\right)$ affinity data for the 43 variants of A15 towards: (A) mAb SD6; (B) mAb 4C4. Peptides displaying $\mathrm{IC}_{50 \text { rel }}$ and/or $K_{\mathrm{D} \text { rel }}$ values too high to be accurately measured are represented by bars truncated at 100 .

Pro was reflected in a complete absence of binding when Pro was replacing residues within the RGD triplet or the short helical stretch (Verdaguer et al., 1995, 1998) at Asp143-Leu147. Replacement at the $\mathrm{N}$-terminal region did not affect binding in positions 137 and 140, but produced a slight decrease and a total loss in antigenicity for positions 138 and 139, respectively. This agrees with recent observations that Ser139 participates in important polar interactions (Verdaguer et al., 1998) in which Pro is unable to engage. Next, we performed a Ser scan, given the striking preservation of antigenicity in site A variants having Ser at critical positions (Verdaguer et al., 1998). Ser replacements at the 137-142 region are in general well-tolerated, including positions 141 and 142, corresponding to Arg and Gly of the RGD motif. These two peptides, A15(141S) and A15(142S), were about an order of magnitude less antigenic than A15 but still clearly reactive. On the other hand, changes at either Asp143, Leu144 or Leu147 were clearly detrimental to recognition, a result which can be explained by (i) the role of the Asp residue of RGD in antibody recognition, and (ii) the fact that both Leu144 and Leu147 are involved in hydrophobic interactions in all available three-dimensional structures of peptide A15-antibody complexes (Verdaguer et al., 1995, 1998).

A third group of variant peptides incorporated replacements at positions 138,145 and 147 to illustrate the subtle effects that structural variation can 
bring about in antibody recognition. For instance, replacements with charged basic (Lys, Arg) residues at Ala138 are better tolerated by mAb 4C4 than by SD6 (Fig. 3 and Table 1). This is in agreement with the higher percentage of residue contact observed for the latter $\mathrm{mAb}$ in the crystal structure of A15-antibody complexes (Verdaguer et al., 1998). Non-polar aliphatic or aromatic amino acids seem to be acceptable by both mAbs at this position. Changes at position 145 (Ala) are similarly interesting. Thus, while SD6 does not recognize peptides with non-polar replacements, 4C4 easily binds the same mutated peptides. Even more striking is the reactivity of both mAbs with the Glu-replaced peptide, whereas the Asp mutation is completely inactive. Finally, position 147 provides the most critical differentiation between both mAbs: while SD6 is quite tolerant to mutations (except Asp), 4C4 is extremely sensitive to changes at this position.

The mAb-peptide affinities measurable by SPR in this study range from $10^{6}$ to $10^{8} \mathrm{M}^{-1}$. As shown in Table 1 , association rate constants contribute to differences in affinities in a less significant way than do dissociation events, as seen by the only 10 -fold range of variation among $k_{\mathrm{a}}$ values $\left(0.6 \times 10^{5}\right.$ to $\left.6 \times 10^{5} \mathrm{M}^{-1} \mathrm{~s}^{-1}\right)$, compared with the 100 -fold range variation for $k_{\mathrm{d}}\left(6 \times 10^{-4}\right.$ to $\left.560 \times 10^{-4} \mathrm{~s}^{-1}\right)$. Affinities seem to be due to faster dissociation of less stable complexes rather than to lower association rates, as previously described (Altschuh et al., 1992; VanCott et al., 1994; England et al., 1997).

\section{Acknowledgements}

We are grateful to Serveis Cientifico-tècnics (SCT, University of Barcelona, Spain) for the use of the BIACORE 1000 instrument and for supplying all the BIAcertified reagents and materials. We thank Dr. Mauricio G. Mateu (CBM-CSIC, Madrid) for the ELISA competition experiments and Dr. Núria Verdaguer, Dr. Ignasi Fita and Wendy Fernández (CID-CSIC, Barcelona), for supplying mAbs SD6 and 4C4. We thank Dr. Maria Luz Valero for supplying the synthetic pentadecapeptides. P.G. thanks the Fundação Calouste Gulbenkian (Lisbon, Portugal) for a doctoral fellowship and the Oporto University (Portugal) for a temporary leave from teaching du- ties. This work was supported by funds from DGES (Spain), grant PB97-0873 and from European Union, grant FAIR5-CT97-3577.

\section{References}

Altschuh, D., Dubs, M.C., Weiss, E., Zeder-Lutz, G., Van Regenmortel, M.H.V., 1992. Determination of kinetic constants for the interactions between a monoclonal antibody and peptides using surface plasmon resonance. Biochemistry 31, 6298.

Carreño, C., Roig, X., Camarero, J., Mateu, M.G., Domingo, E., Giralt, E., Andreu, D., 1992. Studies on antigenic variability of $\mathrm{C}$ strains of foot-and-mouth disease virus by means of synthetic peptides and monoclonal antibodies. Int. J. Pept. Protein Res. 39, 41.

England, P., Brégére, F., Bedouelle, H., 1997. Energetic and kinetic contributions of contact residues of antibody D1.3 in the interaction with lysozyme. Biochemistry 36, 164.

Fägerstam, L.G., Frostell-Karlsson, A., Karlsson, R., Persson, B., Rönnberg, I., 1992. Biospecific interaction analysis using surface plasmon resonance detection applied to kinetic, binding site and concentration analysis. J. Chromatogr. 597, 397.

Feigelstock, D.A., Mateu, M.G., Valero, M.L., Andreu, D., Domingo, E., Palma, E.L., 1996. Emerging foot-and-mouth disease virus variants with antigenically critical amino acid substitutions predicted by model studies using reference viruses. Vaccine 14, 97.

Gomes, P., Giralt, E., Andreu, D., 2000. Surface plasmon resonance screening of synthetic peptides mimicking the immunodominant region of $\mathrm{C}-\mathrm{S} 8 \mathrm{c} 1$ foot-and-mouth disease virus. Vaccine 18, 362.

Hernández, J., Valero, M.L., Andreu, D., Domingo, E., Mateu, M.G., 1996. Antibody and host cell recognition of foot-andmouth disease virus (serotype C) cleaved at the Arg-Gly-Asp (RGD) motif: a structural interpretation. J. Gen. Virol. 77, 257.

Karlsson, R., 1994. Real-time competitive kinetic analysis of interactions between low-molecular weight ligands in solution and surface-immobilized receptors. Anal. Biochem. 221, 142.

Karlsson, R., Fält, A., 1997. Experimental design for kinetic analysis of protein-protein interactions with surface plasmon resonance biosensors. J. Immunol. Methods 200, 121.

Karlsson, R., Ståhlberg, R., 1995. Surface plasmon resonance detection and multispot sensing for direct monitoring of interactions involving low-molecular-weight analytes and for determination of low affinities. Anal. Biochem. 228, 274.

Malmqvist, M., Karlsson, R., 1997. Biomolecular interaction analysis: affinity biosensor technologies for functional analysis of proteins. Curr. Opin. Chem. Biol. 1, 378.

Martínez, M.A., Hernández, J., Piccone, M.E., Palma, E.L., Domingo, E., Knowles, Mateu, M.G., 1991. Two mechanisms of antigenic diversification of foot-and-mouth disease virus. Virology 184, 695.

Mateu, M.G., Andreu, D., Carreño, C., Roig, X., Cairó, J.J., Camarero, J.A., Giralt, E., Domingo, E., 1992. Non-additive 
effects of multiple amino acid substitutions on antigen-antibody recognition. Eur. J. Immunol. 22, 1385.

Mateu, M.G., Valero, M.L., Andreu, D., Domingo, E., 1996. Systematic replacement of amino acid residues within an Arg-Gly-Asp-containing loop of foot-and-mouth disease virus and effect on cell recognition. J. Biol. Chem. 271, 12814.

Morton, T.A., Myszka, D.G., Chaiken, I.M., 1995. Interpreting complex binding kinetics fro optical biosensors: a comparison of analysis by linearization, the integrated rate equation and numerical integration. Anal. Biochem. 227, 176.

Myszka, D.G., Morton, T.A., Doyle, M.L., Chaiken, I.M., 1997. Kinetic analysis of a protein antigen-antibody interaction limited by mass transport on an optical biosensor. Biophys. Chem. 64, 127.

Oddie, G.W., Gruen, L.C., Odgers, G.A., King, L.G., Kortt, A.A., 1997. Identification and minimization of nonideal binding effects in BIAcore analysis: ferritin/anti-ferritin Fab' interaction as a model system. Anal. Biochem. 244, 301.

O'Shannessy, D.J., Winzor, D.J., 1996. Interpretation of deviations to pseudo-first-order kinetic behavior in the characterization of ligand binding by biosensor technology. Anal. Biochem. 236, 275

O'Shannessy, D.J., Brigham-Burke, M., Soneson, K.K., Hensley, P., Brookes, I., 1993. Determination of rate and equilibrium constants for macromolecular interactions using surface plasmon resonance: use of non-linear least squares analysis methods. Anal. Biochem. 212, 457.
Schuck, P., 1997a. Use of surface plasmon resonance to probe the equilibrium and dynamic aspects of interactions between biological macromolecules. Ann. Rev. Biophys. Biomol. Struct. 26, 541.

Schuck, P., 1997b. Reliable determination of binding affinity and kinetics using surface plasmon resonance biosensors. Curr. Opin. Biotechnol. 8, 498.

VanCott, T.C., Bethke, F.R., Polonis, V.R., Gorny, M.K., ZollaPazner, S., Redfield, R.R., Birx, D.L., 1994. Dissociation rate of antibody-gp120 binding interactions is predictive of V3 mediated neutralization of HIV-1. J. Immunol. 153, 449.

Van Regenmortel, M.H.V., Altschuh, D., Pellequer, J.L., RichaletSécordel, P., Saunal, H., Wiley, J.A., Zeder-Lutz, G., 1994. Analysis of viral antigens using biosensor technology. Methods: A Comp. Meth. Enzymol. 6, 177.

Verdaguer, N., Mateu, M.G., Andreu, D., Giralt, E., Domingo, E., Fita, I., 1995. Structure of the major antigenic loop of footand-mouth disease virus complexed with a neutralizing antibody: direct involvement of the Arg-Gly-Asp motif in the interaction. EMBO J. 14, 1690.

Verdaguer, N., Sevilla, N., Valero, M.L., Stuart, D., Brocchi, E., Andreu, D., Giralt, E., Domingo, E., Mateu, M.G., Fita, I., 1998. A similar pattern of interaction for different antibodies with a major antigenic site of foot-and-mouth disease virus: implications for intratypic antigenic variation. J. Virol. 72, 739. 